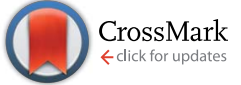

Cite this: J. Mater. Chem. A, 2015, 3, 16302

Received 15th May 2015

Accepted 1st July 2015

DOI: $10.1039 / \mathrm{c} 5 \mathrm{ta0} 3571 \mathrm{f}$

www.rsc.org/MaterialsA

\section{High power density of reverse electrodialysis with pore-filling ion exchange membranes and a high- open-area spacer $\dagger$}

\author{
Han-Ki Kim,,$^{\mathrm{a}}$ Mi-Soon Lee, $\dot{t}^{\mathrm{b}}$ Seo-Yoon Lee, ${ }^{\mathrm{a}}$ Young-Woo Choi, ${ }^{\mathrm{b}}$ Nam-Jo Jeong ${ }^{\mathrm{a}}$ \\ and Chan-Soo Kim*a
}

In the present study, a novel reverse electrodialysis (RED) stack with ultrathin lab-made pore-filling membranes and a high-open-area spacer was proposed to enhance the gross power density. The proposed stack had much lower internal resistance than a typical RED stack at optimum flow rates of seawater and river water. Therefore, a gross power density of $2.4 \mathrm{~W} \mathrm{~m}^{-2}$ was achieved.

\section{Introduction}

Salinity gradient power (SGP), also called blue energy, is a newly emerging form of marine renewable energy. SGP is the energy available from the salinity difference between seawater and river water, which respectively have high and low salt concentrations. The SGP energy potential between typical seawater and river water is $231 \mathrm{~m}$ ( $\sim 23 \mathrm{~atm}$.) of hydraulic water head. The global energy potential is estimated to be 2.4-2.6 TW, which is $\sim 80 \%$ of the global electricity demand. ${ }^{1-3}$

Among membrane-based blue energy technologies, reverse electrodialysis (RED), the opposite process of electrodialysis (ED), has been applied practically. RED uses a stack of alternating cation (CEM) and anion (AEM) exchange membranes. For RED to find greater use, a high power density (power generated per membrane area) is essential. By increasing the power density, the membrane demand and RED stack size can be decreased. ${ }^{4}$ Thus far, typical commercially available RED membranes have shown a maximum power density of $2.2 \mathrm{~W} \mathrm{~m}^{-2}$. $^{5}$

In a typical RED stack, the spacer is an essential component that contributes greatly to the RED performance. ${ }^{5,6}$ The spacer thickness influences the electrical resistance of the RED stack. The threads of the spacers attached to the membrane surface hinder contact between the feed water and the ion exchange membranes (IEMs) by the so-called shadow effect. ${ }^{6,7}$ The shadow effect is related to the open area of the spacer. Therefore, it is essential to select a spacer with both small thickness

${ }^{a} J e j u$ Global Research Center, Korea Institute of Energy Research, 200, Haemajihaean-ro, Gujwa-eup, Jeju 695-971, South Korea. E-mail: damulkim@kier. re.kr; Fax: +82-64-805-2203; Tel: +82-64-800-2251

${ }^{b}$ Hydrogen and Fuel Cell Center for Industry, Academy and Laboratory, Korea Institute of Energy Research, 20-41, Sinjaesaengeneoji-ro, Haseo-myeon, Buan-gun, Jeolllabukdo 579-814, South Korea

$\dagger$ Electronic supplementary information (ESI) available. See DOI: $10.1039 / \mathrm{c} 5 \mathrm{ta} 03571 \mathrm{f}$

\$ These authors contributed equally to the present paper. and large open area. By reducing the spacer thickness below $100 \mu \mathrm{m}$, Vermaas et al. ${ }^{5}$ achieved a gross power density of $2.2 \mathrm{~W}$ $\mathrm{m}^{-2}$ using commercial IEMs. If there is no spacer in the RED stack, the membranes require additional treatments to increase the IEM performance. ${ }^{8-10}$

The IEM also strongly influences the performance, specifically, the power density, of the RED stack. ${ }^{2,11,12}$ Although studies have, over the last decade, improved the IEM characteristics, they do not yet match the expected characteristics for RED. ${ }^{2}$ Generally, IEMs for ion separation processes require high strength and long lifetime regardless of the electrical resistance and thickness; however, IEMs for RED require low electrical resistance and high permselectivity. ${ }^{13}$

Many studies have attempted to develop IEMs for RED. Güler et $a .^{2}{ }^{2}$ were the first to design IEMs for RED. They achieved a power density of $1.27 \mathrm{~W} \mathrm{~m}^{-2}$ using tailor-made membranes consisting of halogenated polyethers such as polyepichlorohydrin (PECH). ${ }^{2}$ They also developed microstructured IEMs for a spacer-free RED stack and achieved up to $20 \%$ improvement in the RED performance. ${ }^{9}$ Nevertheless, most present IEMs for RED still do not possess both the thinness and the mechanical strength required for higher power density of the RED stack. To solve this problem, we have developed porefilling-type IEMs for RED. For the first time, Yamaguchi proposed pore filling membranes for polymer electrolyte fuel cells. ${ }^{14}$ A pore-filling membrane consists of a very thin porous substrate to provide mechanical strength and an electrolyte polymer in the substrate pores to allow ion conductivity. Meanwhile, electrolyte-polymer-filled pores should have high ion exchange capacity (IEC) to increase the ion conductivity.

In the present study, we developed a novel RED stack with lab-made pore-filling IEMs and specific spacers to achieve higher power density in RED. We determined the gross power density to confirm the performance and internal resistance of our proposed RED stack. 


\section{Experimental}

\section{RED stack}

The RED stack (Fig. 1) comprised two end plates $(10 \mathrm{~cm} \times$ $10 \mathrm{~cm} \times 1.5 \mathrm{~cm}$ ) made of acrylic resin and five cell pairs. Each cell pair contained a CEM, an AEM (effective area: $19.6 \mathrm{~cm}^{2}$ ), spacers, and gaskets. An additional CEM for shielding was located near the electrode to maintain the condition of the electrode compartment. Except for the shielding membrane, CEMs and AEMs were alternately stacked between the electrodes. PTFE gaskets (thickness: $100 \mu \mathrm{m}$, Tommy Hecco, South Korea) and spacers (DS Mesh, South Korea) were installed to prevent contact with membranes and provide a channel for the feed solutions. Table 1 lists the characteristics of the spacers used in this study. The electrodes (diameter: $50 \mathrm{~mm}$ ) were made of platinum clad niobium mesh (Sung Wing Technology Co., Hong Kong, China). They were mechanically connected to titanium current collectors.

$0.05 \mathrm{M}$ of potassium hexacyanoferrate(II) and potassium hexacyanoferrate(III) (EP grade, Daejung, South Korea) mixed solution was used as the electrode solution and $0.5 \mathrm{M}$ of sodium sulphate (EP grade, Daejung, South Korea) as the supporting electrolyte. Viton ${ }^{\circledR}$ tubing was used to prevent oxygen transfer to maintain the condition of the electrode solution. Artificial seawater $(0.58 \mathrm{M} \mathrm{NaCl})$ and river water $(0.017 \mathrm{M} \mathrm{NaCl})$ were used as the feed solutions. The flow rate was maintained at $50 \mathrm{~mL}$ $\min ^{-1}$ in all experiments. To investigate the effect of the flow rate on the RED performance, flow rates of seawater and river water were equally changed from 5 to $100 \mathrm{~mL} \mathrm{~min}^{-1}$, which corresponded to 1 to $20 \mathrm{~mL}$ per min per cell, respectively. The power density was measured by a linear potential sweep using a potentiostat (ZIVE SP2, Wonatech, South Korea) with a sweep rate of $40 \mathrm{mV} \mathrm{s}^{-1}$. The internal resistance of the RED stack was estimated as the resistance at the highest power density. ${ }^{4}$

\section{Pore-filling membranes}

We developed three different pore-filling membranes for the RED system: one anion exchange membrane (KIER-AEM1) and two types of cation exchange membranes (KIER-CEM1 and KIERCEM2). KIER-AEM1 is an inner membrane for anion transport; it consists of a polymer cross-linked using $N, N$-bis(acryloyl)piperazine and (vinylbenzyl)trimethylammonium chloride (1: 11.01

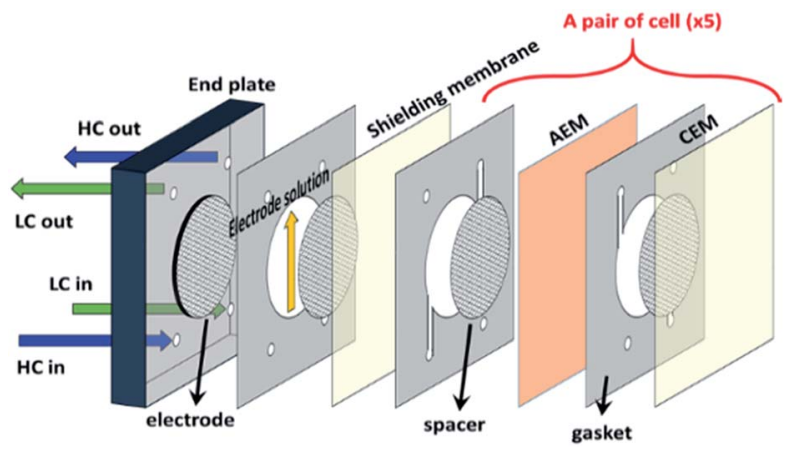

Fig. 1 Schematic diagram of the RED stack.
Table 1 Characteristics of spacers used in this study

\begin{tabular}{lcll}
\hline Name & $\begin{array}{l}\text { Thickness } \\
(\mu \mathrm{m})\end{array}$ & $\begin{array}{l}\text { Mesh opening } \\
(\mu \mathrm{m})\end{array}$ & $\begin{array}{l}\text { Open area } \\
(\%)\end{array}$ \\
\hline Econo 90-20D & 100 & 237 & 70.6 \\
Econo 70-30D & 94 & 308 & 72.0 \\
Econo Black 130-20D & 100 & 916 & 81.3 \\
Econo Black 180-20D & 64 & 444 & 63.2
\end{tabular}

mol $\mathrm{mol}^{-1}$ ) in a porous polyolefin substrate (see the ESI $\dagger$ for details). KIER-CEM1 is another inner membrane for cation transport; it consists of a polymer cross-linked using $N, N^{\prime}$ ethylenebis(acrylamide) and vinyl sulphonic acid (1:8.83 mol $\mathrm{mol}^{-1}$ ). KIER-AEM1 and KIER-CEM1 were used to enable enhanced ion passage through the membranes. KIER-CEM2 is a shielding membrane to prevent the crossover of redox couples and water back-diffusion toward the electrode sides and is used for cation transport; it consists of a cross-linked polymer with $N, N^{\prime}$-ethylenebis(acrylamide) and acrylamido-2-methyl-1-propanesulphonic acid $\left(1: 3.25 \mathrm{~mol} \mathrm{~mol}^{-1}\right)$. To improve the power output in an RED stack, the shielding membrane should have higher permselectivity rather than fast ion transport. As reported in our previous paper, ${ }^{\mathbf{1 5}}$ the dry thickness of the resulting KIER-AEM1 is $\sim 23 \mu \mathrm{m}$; KIER-CEM1 and KIER-CEM2 had similar dimensions. Furthermore, the prepared membranes showed very high mechanical strength (tensile strength of $130 \mathrm{MPa}) .{ }^{16} \mathrm{In}$ this study, the prepared membranes were physicochemically and electrochemically characterized in terms of the swollen membrane thickness $\left(T_{\mathrm{w}}\right)$, swelling degree (SD), ion exchange capacity (IEC), fixed charge density $\left(\mathrm{CD}_{\mathrm{fix}}\right)$, membrane resistance $\left(R_{\mathrm{m}}\right)$, and permselectivity $(\alpha)$ (see the ESI $\dagger$ for details).

\section{Results and discussion}

The lab-made membranes were compared with commercially available ones, as listed in Table 2. An IEM's SD in a solution is a crucial factor for determining its $\mathrm{CD}_{\text {fix }}$ (see the $\mathrm{ESI}^{\dagger}$ for details). ${ }^{17}$ Furthermore, the IEC reflects the ion-transport capacity to generate ionic current, being converted to electronic current at the electrodes in the RED process. Many studies on RED derived $\mathrm{CD}_{\text {fix }}$ from the relationship between an IEM's IEC and SD. Typically, $\mathrm{CD}_{\mathrm{fix}}$ is denoted as an equivalent of the IEMs' functional groups per weight of its absorbed water. ${ }^{18}$ This calculation does not consider the geometry of the membrane structure. However, the geometry should definitely be considered because some IEMs such as pore-filling membranes, with alternating microstructures between the electrolyte and nonelectrolyte polymers, show different water uptakes and dimensional changes (we will evaluate $\mathrm{CD}_{\text {fix }}$ for various IEMs in greater detail in a separate paper). Therefore, we insist that the dimensional change in the swollen IEM is a more feasible means of determining $\mathrm{CD}_{\text {fix }}$ than the weight change in the absorbed water. Table 2 shows that $\mathrm{CD}_{\text {fix }}$ of the lab-made membranes is comparable to that of commercially available membranes. Długołecki et al. noted that an IEM's fixed charge 
density strongly affects its permselectivity and resistance. ${ }^{\mathbf{1 3}}$ However, the membrane resistance of the KIER lab-made IEMs is very low compared to that of commercial IEMs, although all CEMs and AEMs had similar $\mathrm{CD}_{\text {fix }}$ and permselectivities. This result indicates that the membrane resistance definitely depends on the membrane thickness rather than on $\mathrm{CD}_{\text {fix }}$. Furthermore, we could not conclusively prove the correlation between $\mathrm{CD}_{\text {fix }}$ and permselectivity. Instead, we consider that the membrane morphology more greatly affects the membrane permselectivity. The membrane resistance has a functional relationship between the IEC and the IEM thickness. The iontransport capacity and membrane thickness strongly influence the power density in RED. In other words, the high ionic resistance of IEM leads to a negative effect such as an increase in the resistance in the RED stack at low concentrations. ${ }^{19}$ Therefore, we developed lab-made IEMs with a low membrane resistance and high ion-transport capacity using the pore-filling technique.

Fig. 2 shows the gross power density curves with respect to different nonconductive spacers (thickness: $\sim 100 \mu \mathrm{m}$ ). In this experiment, Selemion (AMV and CMV) membranes were used exclusively to compare the effect of the spacers. A gross power density of $1.8 \mathrm{~W} \mathrm{~m}^{-2}$ was obtained when the Black 130-20D spacer was used; this spacer had the highest open area $(81.3 \%)$ among all the spacers. Several previous studies used thin and dimensional spacers to achieve a higher power density., However, the open areas of spacers with a plain weave were only 49-53\%. Therefore, the highest net power density achieved was only $1.2 \mathrm{~W} \mathrm{~m} \mathrm{~m}^{-2} \cdot{ }^{5}$ Another study introduced dimensionally twisted structured spacers for RED. ${ }^{6}$ This spacer had $83 \%$ open area but thickness over $200 \mu \mathrm{m}$. Consequently, the net power density achieved was less than $0.8 \mathrm{~W} \mathrm{~m}^{-2}$. In contrast, the pressure drop in our developed RED stack with a high-openarea spacer was less than $100 \mathrm{kPa}$, which was lower than that in previous studies. Furthermore, the high-open-area spacer conserved more gross power density without energy loss. Finally, increasing the effective area of the IEMs affected the current density. As shown in Fig. 2, the current density on the peak power density in each experiment increased with the open area. Upon reducing the shadow effect, the redox couples in the electrode solution had more opportunity for the redox reaction

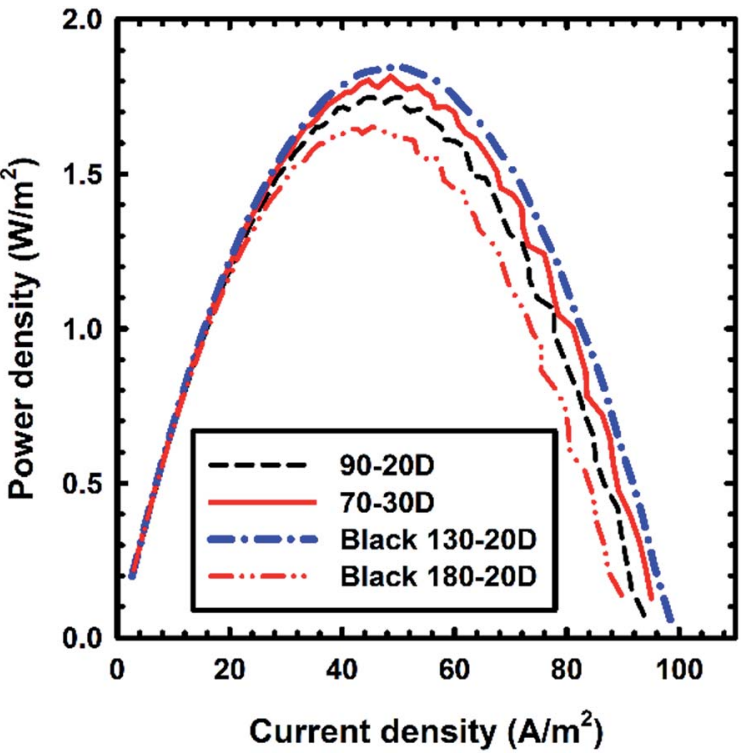

Fig. 2 Gross power density curves with respect to nonconductive spacers.

on the enlarged active area. Therefore, the current density increased.

The internal resistance comprises the ohmic resistance $\left(R_{\text {ohmic }}\right)$, boundary layer resistance $\left(R_{\mathrm{BL}}\right)$, and bulk layer resistance $\left(R_{\Delta c}\right)$ (eqn (1)). ${ }^{5}$ The ohmic resistance can be predicted from the stack design and material properties using eqn (2). ${ }^{\mathbf{2 0 , 2 1}}$ In contrast, the boundary layer resistance and bulk layer resistance are non-ohmic resistances. The bulk layer resistance, which is induced by the concentration change, can be estimated using eqn (3). The boundary layer resistance was estimated as the remainder of the internal resistance component in eqn (1). ${ }^{5,10}$ The low internal resistance of the RED stack afforded high gross power density. ${ }^{22}$

$$
\begin{gathered}
R_{\mathrm{i}}=R_{\mathrm{ohmic}}+R_{\Delta c}+R_{\mathrm{BL}} \\
R_{\mathrm{ohmic}}=N / A\left(R_{\mathrm{AEM}}+R_{\mathrm{CEM}}+d_{\mathrm{c}} / \kappa_{\mathrm{c}}+d_{\mathrm{d}} / \kappa_{\mathrm{d}}\right) \\
R_{\Delta c}=(\alpha R T) /(F J) \ln \left(\Delta a_{\mathrm{d}} / \Delta a_{\mathrm{c}}\right)
\end{gathered}
$$

\begin{tabular}{|c|c|c|c|c|c|c|c|}
\hline FKS & FumaTech GmbH, Germany & 36 & 0.220 & 1.54 (ref. 13) & 7.0 & 1.50 (ref. 13) & 94.2 (ref. 13) \\
\hline CMX & Tokuyama Co., Japan & 172 & 0.222 & 1.62 (ref. 13) & 7.3 & 2.91 (ref. 13) & 99.0 (ref. 13) \\
\hline AMX & Tokuyama Co., Japan & 129 & 0.175 & 1.25 (ref. 13) & 7.1 & 2.35 (ref. 13) & 90.7 (ref. 13) \\
\hline CMV & Asahi Glass Co. Ltd, Japan & 110 & 0.296 & 2.01 (ref. 13) & 6.8 & 2.29 (ref. 13) & 98.8 (ref. 13) \\
\hline KIER-AEM1 & Lab-made & 27 & 0.219 & 1.55 & 7.1 & 0.28 & 91.8 \\
\hline KIER-CEM2 & Lab-made & 27 & 0.217 & 1.42 & 6.5 & 0.72 & 99.2 \\
\hline
\end{tabular}

Table 2 Comparison of membrane characteristics between lab-made and commercially available membranes 
Fig. 3 shows the contribution of the internal resistances of the RED stacks with respect to the membrane compositions. The lab-made IEMs showed lower internal resistance than the commercial IEMs. In particular, their ohmic resistance was 1.5 times lower than that of the FAS/FKS combination, which has the lowest electrical resistance in commercial membranes. Furthermore, the bulk layer resistance was 1.3 times lower than that of FAS/FKS. These results indicated that lab-made IEMs transported more target ions from high-concentration compartments to low-concentration compartments in a given time. Therefore, the electrical conductivity of the low concentration compartments increased and the bulk layer resistance decreased. Generally, the swelling of dry IEMs was enhanced by increasing the IEC, and the water volume fraction within the IEMs had a trade-off relationship with the internal resistance. ${ }^{23}$ However, this was not the case with the RED stack with porefilling membranes. Although the lab-made IEMs had comparable IECs to the commercial IEMs, they did not have sufficient volume for water uptake because the pore-filling membrane showed less volume change with swelling. Therefore, water should penetrate the free volume within the fixed functional groups. Eventually, lab-made IEMs conserved their high fixed charge density after swelling and short ion transfer pathways within the structure.

The IEM thickness is an important parameter influencing the ohmic resistance of the RED stack. The IEM's ohmic resistance decreased with its thickness. ${ }^{11}$ Lab-made IEMs, especially the inner IEMs used in the present study, had around 5 times lower electrical resistance than FAS/FKS, which are homogeneous IEMs. Fast ion transfer through the lab-made IEMs resulted in low boundary layer resistance, and the specific spacers allowed for a greater possibility of ion-membrane contact. With the synergetic effects of lab-made IEMs and spacers, the internal resistance of RED stacks decreased remarkably.

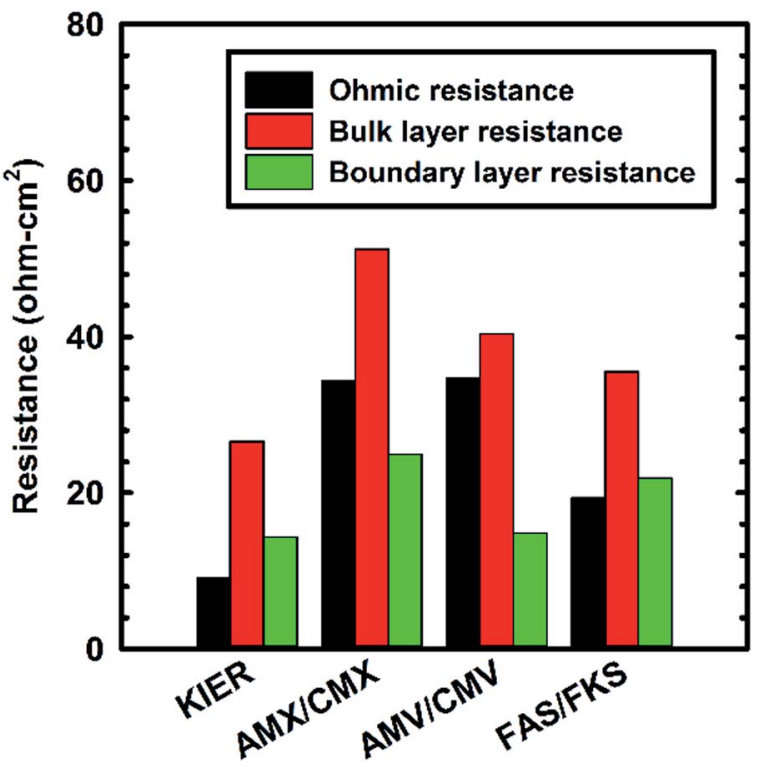

Fig. 3 Internal resistance contributions with respect to IEMs.
Fig. 4 shows the gross power density $\left(P_{\text {gross }}\right)$ of the RED stack with respect to the IEMs. Generally, power is a function of current and external resistance (eqn (4)). According to Kirchhoff's law, the current was substituted as $V_{0} /\left(R_{\mathrm{i}}+R_{\mathrm{u}}\right)$. Then, the highest gross power density can be expected when the stack resistance is equal to the external resistance according to eqn (4). ${ }^{5,13,24}$ In the present study, we achieved a gross power density of $2.4 \mathrm{~W} \mathrm{~m}^{-2}$. This was higher than that achieved in previous studies that used commercial or tailor-made IEMs. ${ }^{2,5}$ In the same RED cell, lab-made IEMs showed 1.4 times higher gross power density than an RED stack with AMV/CMV and 1.3 times higher gross power density than an RED stack with FAS/FKS. The current density was also increased by decreasing the internal resistance of the RED stack. Although the non-ohmic resistance largely contributed to the internal resistance of the RED stack, it was also induced by the physicochemical properties of the IEM, especially the thickness with a fixed charge density. ${ }^{\mathbf{1 1}}$ Therefore, the most important IEM parameter for a RED stack is the thickness; the thickness with a reasonably high fixed charge density directly influences the ohmic resistance, which, in turn, influences the ion transport.

$$
\begin{gathered}
P=I^{2} R_{\mathrm{u}}=\left(V_{0}^{2} R_{\mathrm{u}}\right) /\left(R_{\mathrm{i}}+R_{\mathrm{u}}\right)^{2} \\
P_{\text {gross }}=\left(\mathrm{OCV}^{2}\right) /\left(4 R_{\mathrm{i}} N_{\mathrm{m}}\right)
\end{gathered}
$$

Fig. 5 shows the effect of flow rates of seawater and river water on the OCV and gross power density. The OCV and gross power density increased with the flow rate until a flow rate of

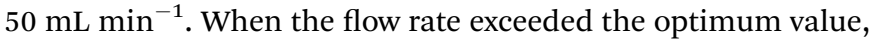
the OCV and gross power density decreased relative to the maximum. These results are similar to previous studies with or without spacers. ${ }^{3,10}$ When the flow rate was $50 \mathrm{~mL} \mathrm{~min}^{-1}$, the experimental OCV value was $92.4 \%$ compared to the theoretical

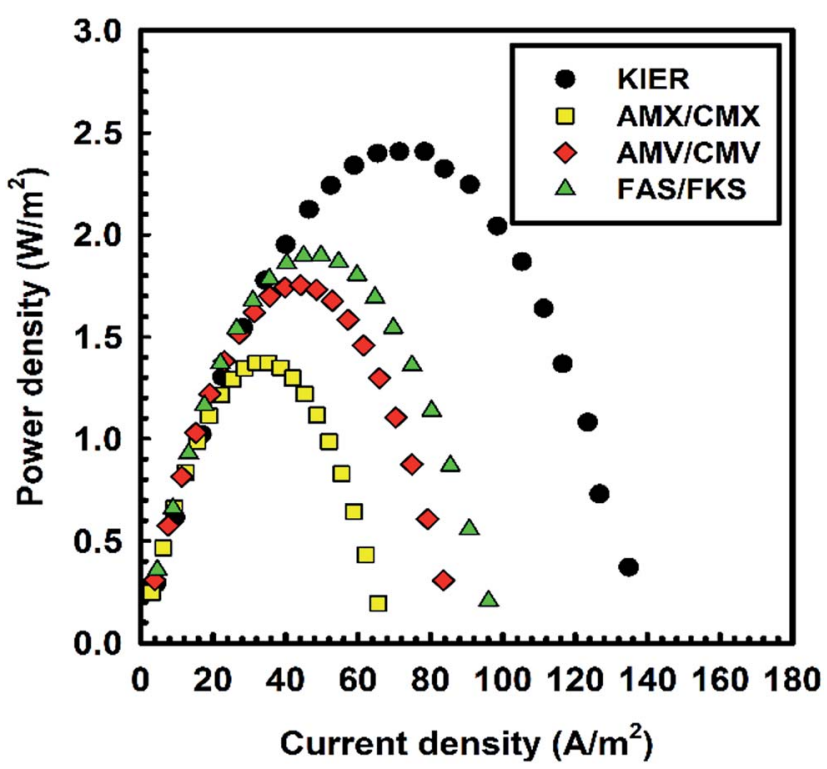

Fig. 4 Gross power density curves with respect to IEMs. 


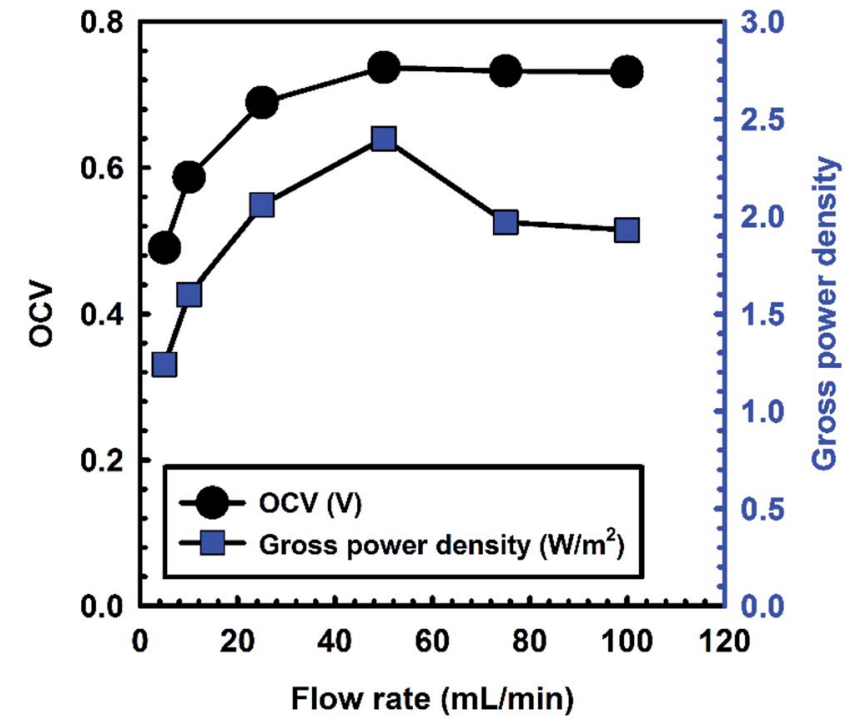

Fig. 5 OCV and gross power density at various flow rates of feed solutions.

value. However, the experimental OCV was $61.4 \%$ compared to the theoretical value at a flow rate of $5 \mathrm{~mL} \mathrm{~min}^{-1}$. This is because of the concentration polarization in the vicinity of membranes and at low flow rates. ${ }^{10}$ As the flow rate increased until the optimum value, the concentration polarization would decrease, resulting in low boundary layer resistance. Therefore, the internal resistance of the RED stack decreased, as shown in Fig. S1. $\dagger$ However, when the flow rate exceeded the optimum value, the internal resistance increased and the gross power density decreased because of the increase in the bulk layer resistance of the low-concentration compartment. Although the OCV was similar to the maximum, the ion concentration in the low-concentration compartment would decrease because of the high flow rate of the feed solution in the RED stack. Therefore, the gross power density decreased when the flow rates exceeded the optimum value. These results indicate that the flow rate is an important factor for controlling the internal resistance of the RED stack.

\section{Conclusions}

In the present study, lab-made pore-filling membranes and a specific spacer were used in an RED stack to increase the gross power density. The ultrathin lab-made IEMs showed extremely low membrane resistances, inducing fast ion transport through the IEMs. The specific spacer developed for RED had an $81.3 \%$ open area. Consequently, the RED stack's current density increased, and the gross power density reached up to $2.4 \mathrm{~W} \mathrm{~m}^{-2}$ at optimum flow rates of feed solutions.

\section{Acknowledgements}

This work was supported by the New \& Renewable Energy Core Technology Program of the Korea Institute of Energy Technology Evaluation and Planning (KETEP), which was granted financial resources from the Ministry of Trade, Industry \& Energy, Republic of Korea (20143030071240), and by the framework of the Research and Development Program of the Korea Institute of Energy Research (KIER) (B5-2481).

\section{Notes and references}

1 O. Levenspiel and N. de Nevers, Science, 1974, 183, 157-160.

2 E. Güler, Y. Zhang, M. Saakes and K. Nijmeijer, ChemSusChem, 2012, 5, 2262-2270.

3 P. Długołęcki, A. Gambier, K. Nijmeijer and M. Wessling, Environ. Sci. Technol., 2009, 43, 6888-6894.

4 J. Veerman, M. Saakes, S. J. Metz and G. J. Harmsen, Environ. Sci. Technol., 2010, 44, 9207-9212.

5 D. A. Vermaas, M. Saakes and K. Nijmeijer, Environ. Sci. Technol., 2011, 45, 7089-7095.

6 D. A. Vermaas, M. Saakes and K. Nijmeijer, J. Membr. Sci., 2014, 453, 312-319.

7 K. Zhang, M. Wang and C. Gao, J. Membr. Sci., 2012, 387-388, 48-53.

8 J. Balster, D. F. Stamatialis and M. Wessling, J. Membr. Sci., 2010, 360, 185-189.

9 E. Güler, R. Elizen, M. Saakes and K. Nijmeijer, J. Membr. Sci., 2014, 458, 136-148.

10 D. A. Vermaas, M. Saakes and K. Nijmeijer, J. Membr. Sci., 2011, 385-386, 234-242.

11 E. Güler, R. Elizen, D. A. Vermaas, M. Saakes and K. Nijmeijer, J. Membr. Sci., 2013, 446, 266-276.

12 J. Veerman, R. M. de Jong, M. Saakes, S. J. Metz and G. J. Harmsen, J. Membr. Sci., 2009, 343, 7-15.

13 P. Długołęcki, K. Nymeijer, S. Metz and M. Wessling, J. Membr. Sci., 2008, 319, 214-222.

14 T. Yamaguchi, F. Miyata and S. Nakao, Adv. Mater., 2003, 15, 1198-1201.

15 M.-S. Lee, T. Kim, S.-H. Park, C.-S. Kim and Y.-W. Choi, J. Mater. Chem., 2012, 22, 13928-13931.

16 H. Kang, M.-S. Lee, W.-J. Sim, T.-H. Yang, K.-H. Shin, Y.-G. Shul and Y.-W. Choi, J. Membr. Sci., 2014, 460, 178184.

17 J. W. Post, J. Veerman, H. V. M. Hamelers, G. J. W. Euverink, S. J. Metz, K. Nymeijer and C. J. N. Buisman, J. Membr. Sci., 2007, 288, 218-230.

18 F. G. Wilhelm, I. Pünt and N. van der Vegt, J. Membr. Sci., 2002, 199, 167-176.

19 P. Długołęcki, B. Anet, S. J. Metz, K. Nijmeijer and M. Wessling, J. Membr. Sci., 2010, 346, 163-171.

20 J. W. Post, H. V. M. Hamelers and C. J. N. Buisman, Environ. Sci. Technol., 2008, 42, 5785-5790.

21 Z. Jia, B. Wang, S. Song and Y. Fan, Renewable Sustainable Energy Rev., 2014, 31, 91-100.

22 S. Pawlowski, P. Sistat, J. G. Crespo and S. Velizarov, J. Membr. Sci., 2014, 471, 72-83.

23 G. M. Geise, M. A. Hickner and B. E. Logan, ACS Appl. Mater. Interfaces, 2013, 5, 10294-10301.

24 A. Daniilidis, D. A. Vermaas, R. Herber and K. Nijmeijer, Renewable Energy, 2014, 64, 123-131. 